\title{
Successful capacitation and homologous fertilization in vitro in Calomys musculinus and Calomys laucha (Rodentia- Sigmodontinae)
}

\author{
A. Lasserre*, E. Cebral and A. D. Vitullo \\ Centro de Estudios Farmacológicos y Botánicos (CEFYBO-CONICET), Serrano 669. (1414), Capital Federal Argentina
}

\begin{abstract}
Small South American rodents of the genus Calomys have been used extensively for virology and ecological research. Previous studies have demonstrated that Calomys musculinus and Calomys laucha have a relatively short oestrous cycle and that superovulation and parthenogenetic activation can be induced. The purpose of this study was to determine the requirements for in vitro manipulation of the male gamete and in vitro fertilization. Two culture media and different concentrations of spermatozoa were tested for their ability to support sperm motility, hyperactivation and the acrosome reaction. The ability of capacitated Calomys spermatozoa to penetrate zona-free hamster eggs was also evaluated. In vitro fertilization was assessed by examining attachment and binding to the zona pellucida, second polar body extrusion, pronucleus formation and the fertilizing sperm tail. The results of the study showed that: (i) Tyrode's albumin lactate pyruvate (TALP) medium was more effective than T6 medium for maintaining sperm motility in vitro; (ii) hyperactivation was achieved with TALP but not with T6; (iii) the acrosome reaction was easily distinguished by light microscopy and depends on time and sperm concentration; (iv) capacitated spermatozoa are able to penetrate zona-free hamster eggs; and (v) superovulated oocytes can be fertilized in vitro. This is the first report of capacitation and in vitro fertilization for Calomys sp. These results provide opportunities to use C. musculinus and C. laucha as new laboratory animals for research into reproductive biology.
\end{abstract}

\section{Introduction}

Calomys, a South American mouse genus, occurs in a variety of habitats including mountain grassland, brushy areas and forest fringes in Argentina, Bolivia, Brazil, Paraguay, Peru, Uruguay and Venezuela (Reig, 1984). Their morphological and ecological diversity make it interesting to consider the presumptive variations in their behaviour. Calomys has epidemiological importance as a natural reservoir of arena viruses, hanta viruses and protozoans hazardous to humans (Weissenbacher et al., 1987, 1990; Mills et al., 1994; Childs et al., 1995). Its several unique characteristics have resulted in adoption of this genus for studies in various biomedical fields. Calomys musculinus and Calomys laucha are easy to breed, have large litter sizes and ovulate spontaneously through the year. Attempts have been made to introduce superovulation and parthenogenetic activation and to culture preimplantation embryos (Lasserre et al., 1998, 1999a,b). Preliminary results demonstrated that the oocytes

*Correspondence address: Instituto de Biología y Medicina Experimental (IBYME-CONICET) Vuelta de Obligado 2490, (1428) Capital Federal, Argentina.

Received 10 November 1999. from C. musculinus and C. laucha have different requirements compared with those of conventional rodents.

Studies to characterize the biological aspects of reproduction require a successful IVF procedure in the species of choice. In this connection, it is essential to evaluate sperm motility, capacitation, the acrosome reaction and the subsequent ability for attachment and binding to, and penetration of, the zona pellucida, oocyte activation and pronuclei formation. It is well known that pre-incubated spermatozoa can undergo capacitation in certain artificial media, although the time required for capacitation varies among species (Toyoda et al., 1971; Yanagimachi, 1970, 1972; Niwa and Chang, 1974).

The present study is part of a broader programme on the reproductive biology of these species in an attempt to consolidate their potential usefulness as an experimental model. The study involved examination of different media, sperm concentration, capacitation time, the acrosome reaction and the time required to complete fertilization. A heterologous sperm penetration assay (Yanagimachi, 1984) was also performed, which evaluates sperm capacitation and the acrosome reaction. On the basis of the results, a successful in vitro fertilization procedure was developed in C. musculinus and C. laucha. 


\section{Materials and Methods}

\section{Animals}

Calomys laucha has been bred in this laboratory since 1993; the colony originates from mice of the Universidad de Córdoba. Calomys musculinus has been bred in this laboratory since 1992; the colony was initiated from two males and one female captured at Donovan, province of San Luis, Argentina. General husbandry and breeding conditions were as described by Hodara et al. (1984, 1989). Female golden hamsters (6-8 weeks old) were provided by Dr C. Barros, Pontificia Universidad Católica de Chile. The animals were maintained under controlled conditions of $14 \mathrm{~h}$ light:10 h dark and were fed with a commercial mouse chow. Food and water were provided ad libitum. Females and males used for experimentation were identified at weaning and maintained in groups of two to three animals until used.

\section{Culture media}

T6 was prepared according to the method of Wood (1987) supplemented with 5\% BSA (Sigma, St Louis, MO). Tyrode's albumin lactate pyruvate (TALP) medium was prepared according to the method of Bavister and Yanagimachi (1977) supplemented with 5\% BSA. M2 medium (Fulton and Whittingham, 1978) contained 4\% BSA. All media were sterilized by filtering. Media were equilibrated under $5 \%$ $\mathrm{CO}_{2}$ in air for at least $2 \mathrm{~h}$ at $37^{\circ} \mathrm{C}$.

\section{Collection of spermatozoa}

Sexually mature (3 months old) males were killed by cervical dislocation. The epididymides were excised and washed in medium to remove any traces of blood. Cauda epididymides were placed in a $0.5 \mathrm{ml}$ drop of medium and covered with mineral oil. The tubules were cut with a pair of sharp iridectomy scissors to allow the dense mass of spermatozoa to flow out freely into medium for $5 \mathrm{~min}$ in an atmosphere of $5 \% \mathrm{CO}_{2}$ in air at $37^{\circ} \mathrm{C}$. The concentration of spermatozoa was determined using a haemocytometer.

\section{Sperm capacitation}

Motility, hyperactivation and the acrosome reaction. Sperm suspensions were incubated for $2 \mathrm{~h}\left(5 \% \mathrm{CO}_{2}\right.$ in air at $\left.37^{\circ} \mathrm{C}\right)$ in either T6 or TALP at concentrations of $1-2 \times 10^{7}$ and $1-2 \times 10^{8}$ spermatozoa $\mathrm{ml}^{-1}$. Motility, hyperactivation and the acrosome reaction were evaluated throughout the incubation period $(0,30,60,90$ and $120 \mathrm{~min})$. The pattern of hyperactivation was analysed by observation under an inverted microscope and was evaluated for the total motile population. The proportion of acrosome-reacted and acrosome-intact spermatozoa was evaluated directly by light microscopy.

Sperm penetration assay. A heterologous sperm penetration assay was performed using zona-free hamster eggs according to the method of Chaudhuri and Yanagimachi (1984) to evaluate sperm fertilizing ability, including capacitation and the acrosome reaction. This part of the study was conducted at the Pontificia Universidad Catolica de Chile. Briefly, 2-3 month-old female hamsters were superovulated by injection of $50 \mathrm{iu}$ equine chorionic gonadotrophin (eCG; Folligon, Intervet) on the morning of day 1 of the oestrous cycle followed by injection of $50 \mathrm{iu}$ human chorionic gonadotrophin (hCG; Choluron, Intervet) $54-58 \mathrm{~h}$ later. Between 15 and $16 \mathrm{~h}$ after hCG injection, oviducts were excised and placed in a dish with M2 medium $+4 \%$ BSA. The oocyte-cumulus complexes in the oviduct were released from the ampulla using a needle. After treatment with $0.1 \%(\mathrm{w} / \mathrm{v})$ hyaluronidase, cumulus-free hamster eggs were isolated and treated in M2 medium ( $\mathrm{pH} 7.4$ ) containing $0.05 \%(\mathrm{w} / \mathrm{v})$ trypsin for $2 \mathrm{~min}$ to remove the zona pellucida. Sperm were incubated to allow capacitation in TALP medium at a concentration of $1-2 \times 10^{7}$ or $1-2 \times 10^{8}$ spermatozoa $\mathrm{ml}^{-1}$. After $90 \mathrm{~min}$ of preincubation, the eggs were inseminated with either $1-2 \times 10^{7}$ or $1-2 \times 10^{6}$ spermatozoa $\mathrm{ml}^{-1}$ and incubated at $37^{\circ} \mathrm{C}$ in $5 \%$ $\mathrm{CO}_{2}$ in air. After 3-4 h of incubation, the eggs were fixed with $2.5 \%(\mathrm{v} / \mathrm{v})$ formalin and stained with $10 \mu \mathrm{g}$ Hoescht $33342 \mathrm{ml}^{-1}$ (Sigma) in Hepes-buffered medium ( $\mathrm{pH}$ 7.4) and examined under a phase-contrast fluorescence microscope. Sperm penetration was evaluated by observation of swelling of the sperm head and decondensation. The number of eggs penetrated and the mean number of spermatozoa per penetrated egg were recorded. Five replicates were carried out for each experiment.

\section{In vitro fertilization}

Source and collection of eggs. Mature C. musculinus and C. laucha females (2 months old) were induced to superovulate as described by Lasserre et al. (1998, 1999a). Briefly, eCG and hCG were injected i.p. 48 h apart, 12 and $15 \mathrm{iu}$, respectively, for C. musculinus and 8 and $8 \mathrm{iu}$, respectively, for C. laucha. Females were killed by cervical dislocation 14-15 h after hCG injection. Cumulus-enclosed eggs were released by puncturing the ampulla into M2 medium containing 4\% BSA and transferred into droplets $(100 \mu \mathrm{l})$ of fresh medium under mineral oil in a plastic Petri dish (35 $\mathrm{mm}$ diameter).

In vitro insemination. After pre-incubation, the spermatozoa were transferred into $100 \mu \mathrm{l}$ TALP medium containing a cumulus-oocyte complex and incubated for $6 \mathrm{~h}$ at $37^{\circ} \mathrm{C}$ in $5 \% \mathrm{CO}_{2}$ in air. The following combinations were tested: (i) sperm capacitation with $1-2 \times 10^{7}$ spermatozoa $\mathrm{ml}^{-1}$ and insemination with $1-2 \times 10^{5}$ or $1-2 \times 10^{6}$; (ii) sperm capacitation with $1-2 \times 10^{8}$ spermatozoa $\mathrm{ml}^{-1}$ and insemination with $1-2 \times 10^{6}$ or $1-2 \times 10^{7}$ spermatozoa $\mathrm{ml}^{-1}$.

Examination of IVF events. The eggs were examined at 2.5, 5.0 and $6.0 \mathrm{~h}$ after insemination. Whole mount egg preparations were examined under a phase-contrast microscope after they were fixed with $2.5 \% \quad(\mathrm{w} / \mathrm{v})$ glutaraldehyde for $20 \mathrm{~min}$ at room temperature and stained 
with Hoescht $33258\left(10 \mu \mathrm{g} \mathrm{ml}^{-1}\right)$ At 2.5 and $5.0 \mathrm{~h}$ after insemination, sperm attachment was examined under the microscope and the number of spermatozoa attached to each egg was determined. After eggs were washed twice and pipetted in and out of a fine-bore pipette about ten times, the number of spermatozoa that remained bound to each egg was recorded, and the eggs were examined for evidence of sperm penetration.

In a second series of experiments, eggs were examined about $6 \mathrm{~h}$ after insemination for extrusion of the second polar body (activated oocytes), for female and male pronuclei and for the presence of a fertilizing sperm tail.

\section{Statistical analysis}

Statistical analyses were performed by means of the Instat program (Graphpad Software, San Diego, CA). ANOVA or the chi-squared test was used for comparisons between groups. Differences resulting in a $P$ value $<0.05$ were considered significant.

\section{Results}

\section{Effect of medium and sperm concentration on sperm motility}

The effect of incubation of Calomys spermatozoa in T6 or TALP medium for $2 \mathrm{~h}$ is shown (Fig. 1). In C. musculinus (Fig. 1a) between 30 and $120 \mathrm{~min}$ of incubation, the percentage of motility decreased in T6 medium more significantly than in TALP medium at both sperm concentrations $\left(1-2 \times 10^{7}\right.$ and 1-2 $\times 10^{8}$ spermatozoa $\mathrm{ml}^{-1}$ ). In C. laucha (Fig. 1b), the same pattern of motility was found for both media $(P<0.001)$. Exposure to T6 induced sperm agglutination (head to head) in both species (data not shown).

\section{Effect of medium and sperm concentration on hyperactivation}

Cauda epididymal spermatozoa were very active immediately after they were suspended in T6 or TALP, showing a very fast progressive linear motility. The motility pattern of Calomys spermatozoa changed during the course of incubation and it was possible to recognize two other patterns within the hyperactivated group: 'circular', in which spermatozoa moved in circles, and 'wriggling', in which spermatozoa showed rapid wriggling and swam in concentric circles.

In C. musculinus, the spermatozoa incubated with T6 medium showed only linear progressive motility and never developed the hyperactivation pattern. In TALP medium, the percentage of spermatozoa showing hyperactivation increased with incubation time up to $90 \mathrm{~min}$ and this value was maintained up to $120 \mathrm{~min}$ (Fig. 2a), despite the different sperm concentrations $(P<0.001)$. In $C$. laucha (Fig. $2 b)$, the percentage of hyperactivation increased progressively up to $60 \mathrm{~min}$ in TALP medium at both sperm concentrations, but at
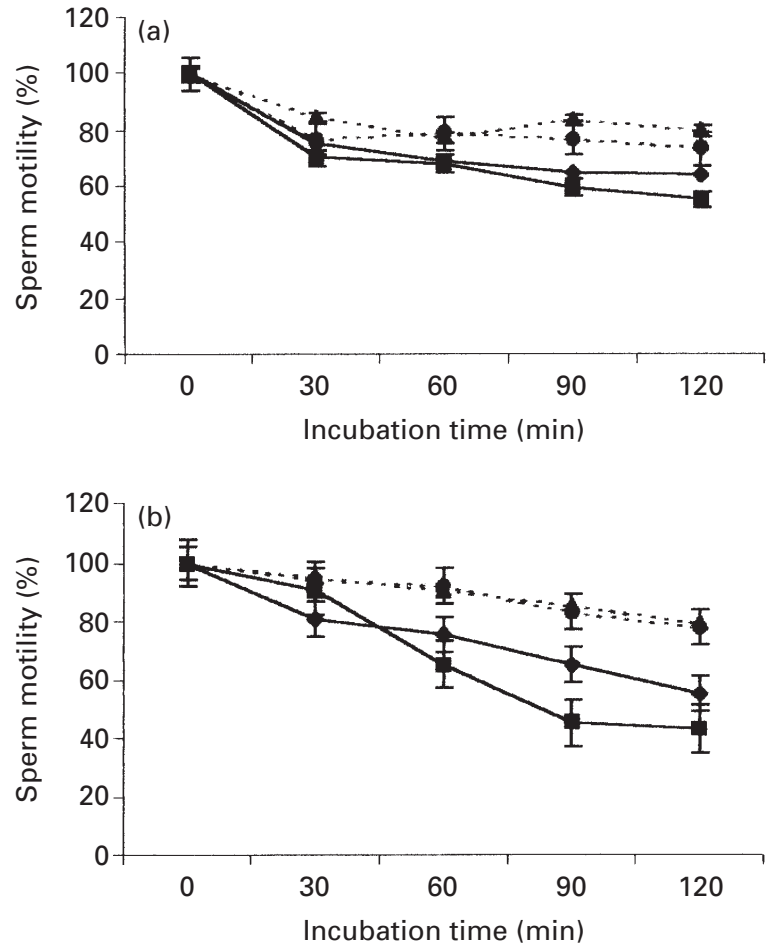

Fig. 1. Effect of medium and sperm concentration on sperm motility in (a) Calomys musculinus and (b) Calomys laucha. Calomys spermatozoa were capacitated for $2 \mathrm{~h}$ in Tyrode's albumin lactate

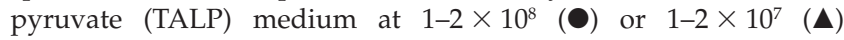
spermatozoa $\mathrm{ml}^{-1}$, or in T6 medium at $1-2 \times 10^{8}(\boldsymbol{\square})$ or $1-2 \times 10^{7}(\boldsymbol{)})$ spermatozoa $\mathrm{ml}^{-1}$. Percentage motility (and SEM) were evaluated for ten males and were analysed by Student's $t$ test. (a) C. musculinus: TALP $+10^{7}$ and $10^{8}$ spermatozoa $\mathrm{ml}^{-1}$ at 120 versus $30 \mathrm{~min}$ of incubation: $P<0.01$. T6 $+10^{7}$ and $10^{8}$ spermatozoa $\mathrm{ml}^{-1}$ at 120 versus $30 \mathrm{~min}: \quad P<0.001$. At $30 \mathrm{~min}$ of incubation: TALP $+10^{7}$ versus $\mathrm{T} 6+10^{7}$ spermatozoa $\mathrm{ml}^{-1}$ and TALP $+10^{8}$ versus $\mathrm{T} 6+10^{8}$ spermatozoa $\mathrm{ml}^{-1}: P<0.001$. At $120 \mathrm{~min}$ of incubation: TALP $+10^{7}$ versus $\mathrm{T} 6+10^{7}$ spermatozoa $\mathrm{ml}^{-1}$ and TALP $+10^{8}$ versus $\mathrm{T} 6+10^{8}$ spermatozoa $\mathrm{ml}^{-1}: P<0.001$. For TALP $+10^{7}$ and $10^{8}$ spermatozoa $\mathrm{ml}^{-1}$ at 120 versus $30 \mathrm{~min}: P<0.01$. For T6 $+10^{7}$ and $10^{8}$ spermatozoa $\mathrm{ml}^{-1}$ at 120 versus $30 \mathrm{~min}: P<0.001$. (b). C. laucha: the same groups were analysed: $P<0.001$ (Student's $t$ test).

1-2 $\times 10^{7}$ spermatozoa $\mathrm{ml}^{-1}$ the hyperactivation rate was lower at 90 and $120 \mathrm{~min}$ than at $1-2 \times 10^{8}$ spermatozoa $\mathrm{ml}^{-1}$. In $\mathrm{T} 6$ medium, a high percentage of spermatozoa became hyperactivated by $30 \mathrm{~min}$ and this value remained constant up to $120 \mathrm{~min}$, at which time the percentage was significantly lower than with TALP medium $(P<0.001)$. The development of a particular motility pattern was time-dependent. Spermatozoa showing linear motility were the most predominant at $0 \mathrm{~min}$, but gradually decreased in number, and the proportion of spermatozoa showing a circular motion increased by $2 \mathrm{~h}$. During incubation, there was a reduction in the diameter of the circular trajectory, and the proportion of spermatozoa showing the wriggling movement was small $(<4 \%)$. 

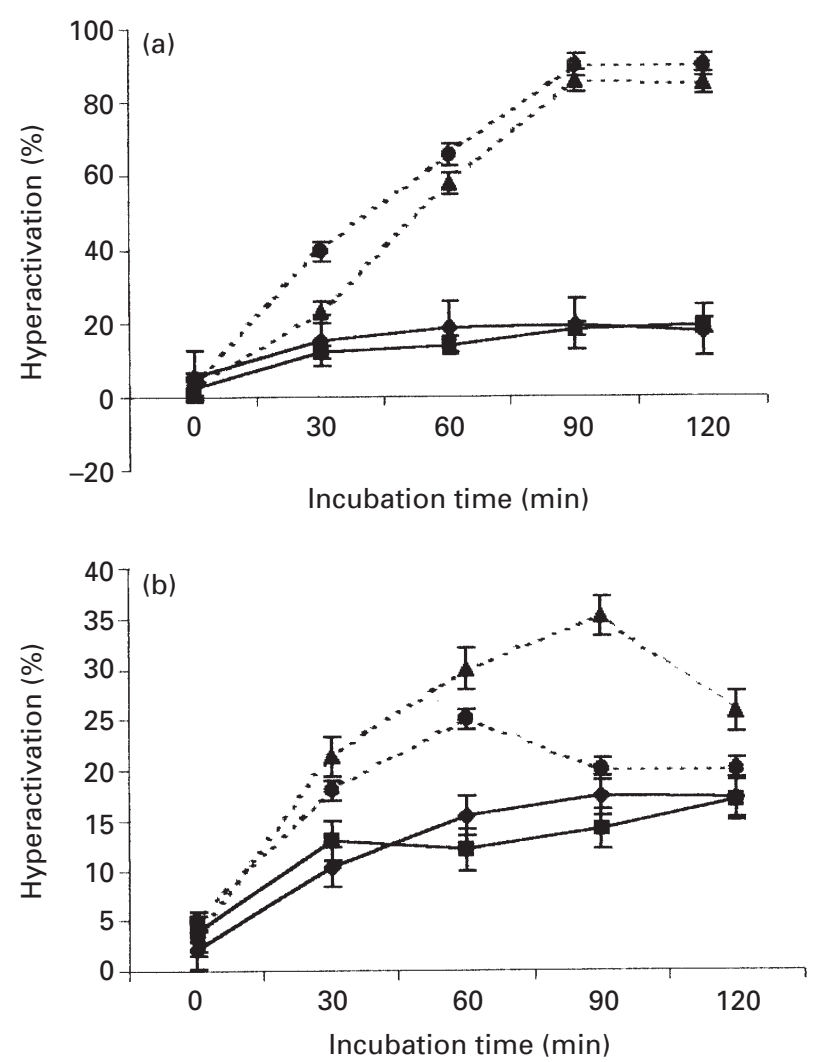

Fig. 2. Effect of medium and concentration on sperm hyperactivation in (a) Calomys musculinus and (b) Calomys laucha. Calomys spermatozoa were capacitated for $2 \mathrm{~h}$ in Tyrode's albumin lactate pyruvate (TALP) medium at $1-2 \times 10^{8}(\bullet)$ or $1-2 \times 10^{7}(\mathbf{\Delta})$ spermatozoa $\mathrm{ml}^{-1}$, or in T6 medium at $1-2 \times 10^{8}(\mathbf{\square})$ or $1-2 \times 10^{7}(\bullet)$ spermatozoa $\mathrm{ml}^{-1}$. Percentages of hyperactivation (and SEM) were evaluated for ten males and analysed by Student's $t$ test. (a) $C$. musculinus: 30 and $120 \mathrm{~min}$ of incubation and the same sperm suspensions as in Fig. 1: $P<0.001$. (b) C. laucha: at $30 \mathrm{~min}$ of incubation: TALP $+10^{7}$ versus T6 $+10^{7}$ spermatozoa $\mathrm{ml}^{-1}: P<0.001$; TALP $+10^{8}$ versus T6 $+10^{8}$ spermatozoa $\mathrm{ml}^{-1}: P<0.01$. At $120 \mathrm{~min}$ of incubation: TALP $+10^{7}$ versus $\mathrm{T} 6+10^{7}$ spermatozoa $\mathrm{ml}^{-1}$ and TALP $+10^{8}$ versus T $6+10^{8}$ spermatozoa $\mathrm{ml}^{-1}: P<0.001$.

\section{Effect of medium and sperm concentration on the acrosome reaction}

C. musculinus spermatozoa have a hooked head, a roughly polygonal nucleus and a flat head base, and the tail inserts eccentrically and ipsilateral to the hook. In contrast, $C$. laucha spermatozoa do not have a hooked head, the nucleus is grossly pyriform but asymmetrical, and the tail inserts centrally in the flat base of the head. It is very easy to distinguish acrosome-intact from acrosome-reacted spermatozoa by light microscopy because the acrosome reaction involves a visible change in head morphology.

The pattern of spontaneous acrosome reactions throughout the incubation period is shown (Fig. 3). In C. musculinus (Fig. 3a) at a concentration of $10^{8}$ spermatozoa $\mathrm{ml}^{-1}$, a maximum percentage of acrosome reactions developed by $60 \mathrm{~min}$ in TALP medium $(P<0.001)$. Under the other conditions $\left(10^{7}\right.$ spermatozoa $\mathrm{ml}^{-1}$ in TALP and $10^{7}$ and
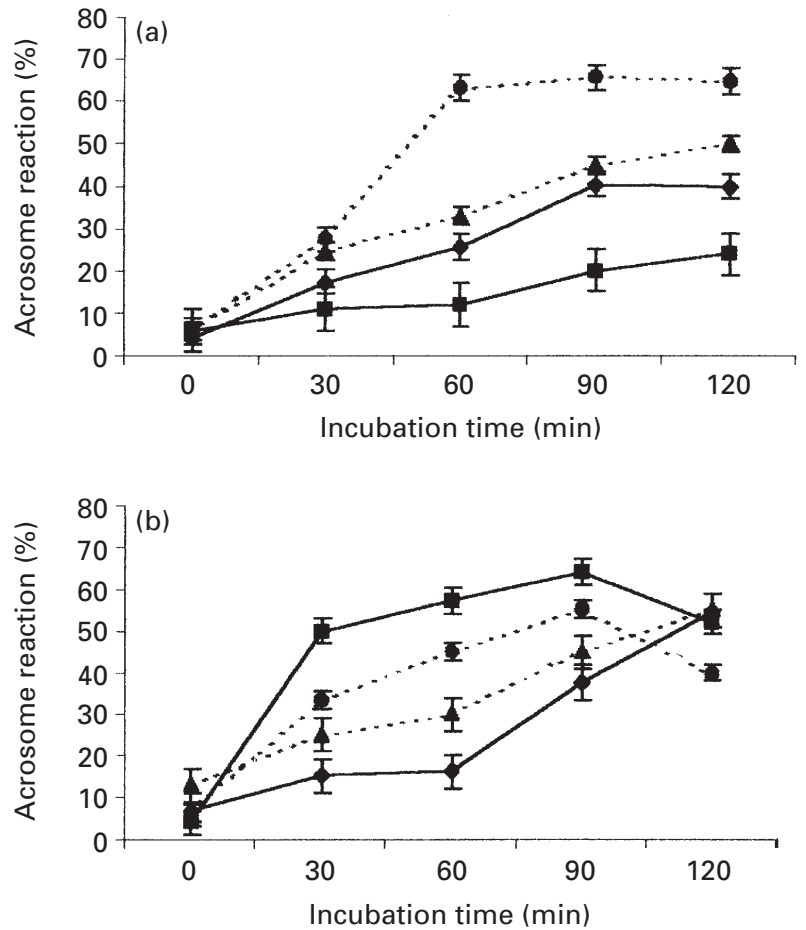

Fig. 3. Effect of the medium and sperm concentration on the acrosome reaction in (a) Calomys musculinus and (b) Calomys laucha. Calomys spermatozoa were capacitated for $2 \mathrm{~h}$ in Tyrode's albumin lactate pyruvate (TALP) medium at $1-2 \times 10^{8}(\mathbf{\bullet})$ or $1-2 \times 10^{7}(\mathbf{A})$ spermatozoa $\mathrm{ml}^{-1}$, or in T6 medium at $1-2 \times 10^{8}(\boldsymbol{\square})$ or $1-2 \times 10^{7}(\boldsymbol{)})$ spermatozoa $\mathrm{ml}^{-1}$. Percentages of acrosome reaction (and SEM) were evaluated for ten males and analysed by Student's $t$ test. (a) $C$. musculinus: for 60 and $120 \mathrm{~min}$ of incubation: TALP $+10^{7}$ versus $\mathrm{T} 6+10^{7}$ spermatozoa $\mathrm{ml}^{-1}$ and TALP $+10^{8}$ versus $\mathrm{T} 6+10^{8}$ spermatozoa $\mathrm{ml}^{-1}: P<0.001$. (b) C. laucha: for 30, 60 and $90 \mathrm{~min}$ of incubation the three groups are significantly different: $P<0.001$. For 120 min of incubation: TALP $+10^{8}$ versus $\mathrm{T} 6+10^{8}$ spermatozoa $\mathrm{ml}^{-1}$ : $P<0.001 ;$ TALP $+10^{7}$ versus $\mathrm{T} 6+10^{7}$ spermatozoa $\mathrm{ml}^{-1}$ : not significant; T6 $+10^{8}$ versus T6 $+10^{7}$ spermatozoa $\mathrm{ml}^{-1}: P<0.05$.

$10^{8}$ spermatozoa $\mathrm{ml}^{-1}$ in T6), the acrosome reaction increased significantly throughout the $120 \mathrm{~min}$ of incubation $(P<0.001)$, and there was no significant difference between 60 and 120 min when $10^{8}$ spermatozoa $\mathrm{ml}^{-1}$ were incubated in TALP medium. In C. laucha (Fig. 3b), the greatest acrosome reaction rate occurred at $90 \mathrm{~min}$ of incubation in both groups in TALP and in T6 media, but although the percentage of acrosome reactions increased from 90 to $120 \mathrm{~min}$ with $10^{7}$ spermatozoa $\mathrm{ml}^{-1}$ in TALP or T6 medium, the percentages were significantly lower with $10^{8}$ spermatozoa $\mathrm{ml}^{-1}$ incubated in TALP or T6 medium at $120 \mathrm{~min}$.

\section{Sperm penetration assay}

The results presented above indicate that Calomys spermatozoa require TALP medium for optimal motility and hyperactivation and also for the acrosome reaction. The effect of the sperm concentration on the ability of Calomys spermatozoa to penetrate zona-free hamster eggs was also 
Table 1. Ability of Calomys musculinus and Calomys laucha spermatozoa incubated in Tyrode's albumin lactate pyruvate medium to penetrate zona-free hamster eggs

\begin{tabular}{lccr}
\hline Species & $\begin{array}{c}\text { Sperm concentration at } \\
\text { pre-incubation/in vitro insemination } \\
\left.\text { (spermatozoa } \mathrm{ml}^{-1}\right)\end{array}$ & $\begin{array}{c}\text { Number of eggs } \\
\text { penetrated } \\
(\%)\end{array}$ & $\begin{array}{c}\text { Number of } \\
\text { penetrating spermatozoa } \\
\text { (mean } \pm \mathrm{SD})\end{array}$ \\
\hline C. musculinus & $1-2 \times 10^{8} / 1-2 \times 10^{7}$ & $26 / 115(22.6)^{* * * *}$ & $6.08 \pm 3.5^{\mathrm{a}}$ \\
C. laucha & $1-2 \times 10^{7} / 1-2 \times 10^{6}$ & $102 / 120(85.0)$ & $12.08 \pm 4.15$ \\
& $1-2 \times 10^{8} / 1-2 \times 10^{7}$ & $21 / 114(18.4)^{* * *}$ & $11.1 \pm 2.8^{\mathrm{a}}$ \\
& $1-2 \times 10^{7} / 1-2 \times 10^{6}$ & $118 / 125(94.4)$ & $14.11 \pm 3.33$ \\
\hline
\end{tabular}

C. musculinus: number of eggs penetrated $22.6 \%$ versus $85 \%,{ }^{* * *} P<0.001$ (chi-squared test); number of penetrating spermatozoa $6.08 \pm 3.5$ versus $12.08 \pm 4.15,{ }^{a} P<0.001$ (Student's $t$ test).

C. laucha: number of eggs penetrated $18.4 \%$ versus $94.4 \%,{ }^{* * *} P<0.001$ (chi-squared test); number of penetrating spermatozoa $11.1 \pm 2.8$ versus $14.11 \pm 3.33,{ }^{a} P<0.001$ (Student's $t$ test).
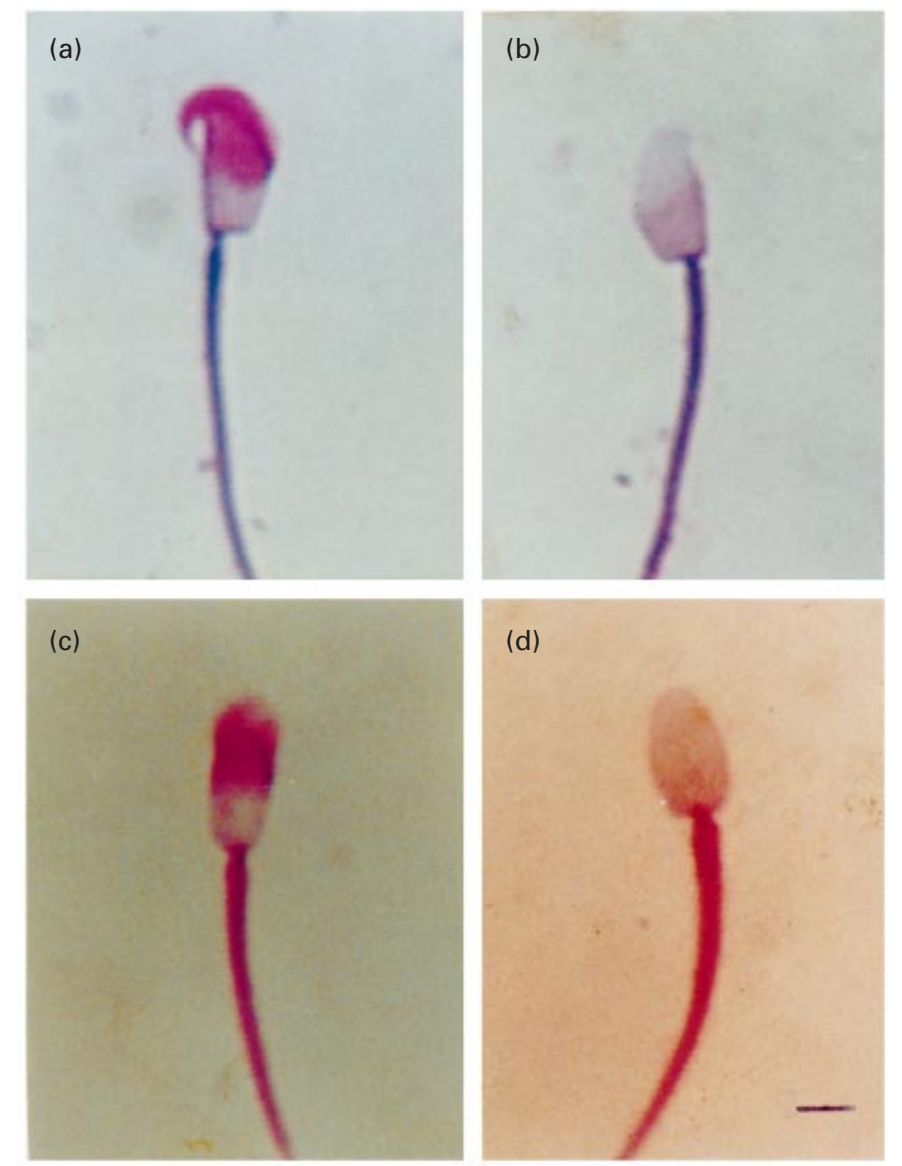

Fig. 4. Sperm and acrosome morphology of Calomys spermatozoa. C. musculinus spermatozoa (a) acrosome-intact and (b) acrosome-reacted. C. laucha spermatozoa (c) acrosome-intact and (d) acrosome-reacted. Scale bar represents $5 \mu \mathrm{m}$.

examined using this medium. In both Calomys sperm penetration assays, the highest percentage of penetrated oocytes and greatest number of penetrating spermatozoa were observed when spermatozoa were incubated at a concentration of $10^{7}$ spermatozoa $\mathrm{ml}^{-1}$ and inseminated at $10^{6}$ spermatozoa $\mathrm{ml}^{-1}$ compared with incubation at $10^{8}$ and insemination at $10^{7}$ spermatozoa $\mathrm{ml}^{-1}(P<0.001)$ (Table 1$)$.

\section{In vitro fertilization}

Attachment and binding to, and penetration of, the zona pellucida by spermatozoa were analysed for both Calomys species (Table 2). At $2.5 \mathrm{~h}$ of incubation, C. musculinus eggs had about two to six spermatozoa attached to the zona pellucida after pre-incubation with $10^{7}$ spermatozoa $\mathrm{ml}^{-1}$ and 
Table 2. Zona attachment, binding and penetration of Calomys musculinus and Calomys laucha spermatozoa using homologous eggs

\begin{tabular}{|c|c|c|c|c|c|c|}
\hline \multirow[b]{2}{*}{ Species } & \multicolumn{2}{|c|}{ Sperm concentration } & \multicolumn{2}{|c|}{$2.5 \mathrm{~h}$} & \multicolumn{2}{|c|}{$5.0 \mathrm{~h}$} \\
\hline & $\begin{array}{c}\text { Pre-incubation } \\
\left(\text { spermatozoa } \mathrm{ml}^{-1} \text { ) }\right.\end{array}$ & $\begin{array}{c}\text { In vitro } \\
\text { insemination } \\
\left(\text { spermatozoa } \mathrm{ml}^{-1}\right)\end{array}$ & $\begin{array}{l}\text { Zona } \\
\text { attachment }\end{array}$ & $\begin{array}{c}\text { Zona } \\
\text { binding }\end{array}$ & $\begin{array}{l}\text { Zona } \\
\text { attachment }\end{array}$ & $\begin{array}{c}\text { Zona } \\
\text { binding }\end{array}$ \\
\hline \multirow[t]{4}{*}{ C. musculinus } & $1-2 \times 10^{8}$ & $1-2 \times 10^{7}$ & - & - & + & + \\
\hline & & $1-2 \times 10^{6}$ & - & - & ++ & + \\
\hline & $1-2 \times 10^{7}$ & $1-2 \times 10^{6}$ & ++ & ++ & +++ & ++++ \\
\hline & & $1-2 \times 10^{5}$ & ++ & ++ & ++ & $++/+++$ \\
\hline \multirow[t]{4}{*}{ C. laucha } & $1-2 \times 10^{8}$ & $1-2 \times 10^{7}$ & - & - & + & + \\
\hline & & $1-2 \times 10^{6}$ & - & - & ++ & + \\
\hline & $1-2 \times 10^{7}$ & $1-2 \times 10^{6}$ & ++ & ++ & +++ & +++ \\
\hline & & $1-2 \times 10^{5}$ & ++ & ++ & ++ & $+/++$ \\
\hline
\end{tabular}

Results are averages of five different experiments.

Number of spermatozoa per egg: -, no spermatozoa; +, one spermatozoon; ++, two to six spermatozoa;,$+++ 7-10$ spermatozoa; ,$++++ 11-18$ spermatozoa.

Table 3. Egg activation and pronucleus formation during in vitro fertilization in Calomys musculinus and Calomys laucha

\begin{tabular}{|c|c|c|c|c|c|c|c|}
\hline \multirow[b]{2}{*}{ Species } & \multicolumn{2}{|c|}{ Sperm concentration } & \multicolumn{3}{|c|}{ Fertilized eggs } & \multicolumn{2}{|c|}{ Unfertilized eggs } \\
\hline & $\begin{array}{c}\text { Pre-incubation } \\
\left(\text { spermatozoa } \mathrm{ml}^{-1}\right)\end{array}$ & $\begin{array}{c}\text { In vitro } \\
\text { insemination } \\
\left(\text { spermatozoa } \mathrm{ml}^{-1}\right)\end{array}$ & $\begin{array}{l}\text { Number } \\
\text { of eggs }\end{array}$ & $\begin{array}{c}\text { Monospermic } \\
\text { eggs }(\%)\end{array}$ & $\begin{array}{l}\text { Polyspermic } \\
\text { eggs }(\%)\end{array}$ & $\begin{array}{c}\text { Activated } \\
(\%)\end{array}$ & $\begin{array}{c}\text { Fragmented } \\
\qquad \%)\end{array}$ \\
\hline \multirow[t]{4}{*}{ C. musculinus } & $1-2 \times 10^{8}$ & $1-2 \times 10^{7}$ & 80 & $5(6.25)$ & $1(1.25)$ & $0(0)$ & $0(0)$ \\
\hline & & $1-2 \times 10^{6}$ & 82 & $15(18.29)^{* *}$ & $2(2.43)$ & $1(1.22)$ & $2(2.43)$ \\
\hline & $1-2 \times 10^{7}$ & $1-2 \times 10^{6}$ & 78 & $50(64.1)^{* a}$ & $1(1.28)$ & $6(7.70)$ & $3(3.85)$ \\
\hline & & $1-2 \times 10^{5}$ & 90 & $44(48.88)$ & $0(0)$ & $4(4.44)$ & $1(1.11)$ \\
\hline \multirow[t]{4}{*}{ C. laucha } & $1-2 \times 10^{8}$ & $1-2 \times 10^{7}$ & 84 & $7(8.33)$ & $3(3.57)$ & $1(1.19)$ & $1(1.19)$ \\
\hline & & $1-2 \times 10^{6}$ & 81 & $19(23.45)^{* * * b}$ & $2(2.47)$ & $0(0)$ & $3(3.70)$ \\
\hline & $1-2 \times 10^{7}$ & $1-2 \times 10^{6}$ & 83 & $58(69.8)^{* * a}$ & $4(4.83)$ & $3(3.61)$ & $2(2.41)$ \\
\hline & & $1-2 \times 10^{5}$ & 82 & $37(45.12)^{\mathrm{b}}$ & $2(2.44)$ & $2(2.44)$ & $3(3.65)$ \\
\hline
\end{tabular}

C. musculinus: $1-2 \times 10^{7}$ versus $1-2 \times 10^{6}$ spermatozoa inseminated per $\mathrm{ml}$ (in vitro insemination): ${ }^{* *} \mathrm{P}<0.01 ; 10^{6}$ versus $10^{5}$ spermatozoa inseminated per ml: ${ }^{*} P<0.05$. Comparisons between the four cases of in vitro insemination: ${ }^{2} P<0.001$ (chi-squared test).

C. laucha: $10^{7}$ versus $10^{6}$ spermatozoa inseminated per $\mathrm{ml}:{ }^{* *} P<0.001 ; 10^{6}$ versus $10^{5}$ spermatozoa inseminated per ml: ${ }^{* *} P<0.01$. Comparisons between the four cases of in vitro insemination: ${ }^{\mathrm{a}} \mathrm{P}<0.001,{ }^{\mathrm{b}} \mathrm{P}<0.01$ (chi-squared test).

insemination with $10^{6}$ or $10^{5}$ spermatozoa $\mathrm{ml}^{-1}$. At $5 \mathrm{~h}$ of incubation, 11-18 spermatozoa were attached and six to ten spermatozoa were bound per egg after pre-incubation with $10^{7}$ spermatozoa $\mathrm{ml}^{-1}$ and insemination with $10^{6}$ spermatozoa $\mathrm{ml}^{-1}$. At $5 \mathrm{~h}$ of incubation spermatozoa had already started to penetrate the eggs. In C. laucha, similar results were observed for the attachment, binding and penetration assays.

At $6 \mathrm{~h}$ after insemination, oocyte activation and pronucleus formation were evaluated (Table 3). For both Calomys species, the highest percentages of monospermic fertilized eggs were obtained after pre-incubation with $10^{7}$ spermatozoa $\mathrm{ml}^{-1}$ and insemination with $10^{6}$ spermatozoa $\mathrm{ml}^{-1}(P<0.001)$.

\section{Discussion}

The present study reports a successful IVF procedure for $C$. musculinus and C. laucha using spermatozoa capacitated in TALP medium and eggs collected $14-16 \mathrm{~h}$ after hCG injection. The results show that in these mice TALP will support sperm motility and in vitro capacitation, as in hamster spermatozoa. The hamster IVF procedure was established using a defined medium containing taurinehipotaurine, identified in sperm extracts from various hamster tissues (Bavister et al., 1978; Meizel et al., 1980; Bavister, 1989). Mrsny et al. (1979) and Meizel et al. (1980) reported that taurine and hipotaurine might play a role in the maintenance and stimulation of sperm motility and in the stimulation of capacitation and the acrosome reaction in vivo. In Calomys spermatozoa, the type of medium was found to affect motility, which decreased with time from 30 to 120 min. The highest percentage of motility was observed when spermatozoa were incubated with TALP, irrespective of the sperm concentration. For both Calomys species, at the same sperm concentration, TALP supported motility better than 
T6 medium for up to 120 min of incubation. In general, the time for capacitation in a culture medium varies among rodent species. For example, $1-2 \mathrm{~h}$ is required for mouse spermatozoa (Toyoda et al., 1971), $2.5 \mathrm{~h}$ for hamster spermatozoa (Yanagimachi, 1970), 5-7 h for rat spermatozoa (Niwa and Chang, 1974) and 8-12 h for guinea-pig spermatozoa (Yanagimachi, 1972). In the present study, C. musculinus spermatozoa were able to penetrate homologous eggs after $90 \mathrm{~min}$ and C. laucha spermatozoa did so after $60 \mathrm{~min}$. In vitro capacitation of mouse spermatozoa under adequate conditions is known to bring about hyperactivation (Yanagimachi, 1970) and for Calomys hyperactivated spermatozoa of both species incubated in TALP medium were characterized by a distinct 'circular' movement first observed at $30 \mathrm{~min}$. Non-hyperactivated spermatozoa showed planar motility, as observed during incubation in T6 medium. The 'figure-of-eight' pattern described for capacitated mouse spermatozoa (Yanagimachi, 1970; Suarez, 1988) was not seen in Calomys spermatozoa.

The spermatozoa of Calomys, like those of other mammals, undergo the acrosome reaction before penetrating the zona pellucida. In the present study, the acrosome reaction was visible under the light microscope in both the hooked heads of C. musculinus spermatozoa and the hookless-heads of C. laucha spermatozoa. In both species, a maximum number has reacted at $90 \mathrm{~min}$ of incubation. However, for IVF, a $60 \mathrm{~min}$ period of sperm pre-incubation was chosen to avoid insemination of a population of $>50 \%$ acrosome-reacted spermatozoa.

The results presented here indicate that TALP is a suitable medium for Calomys spermatozoa in regard to capacitation, the acrosome reaction, and for the hamster test, which confirms the state of capacitated spermatozoa and their ability to fuse with, and be incorporated into, the oocyte. For both Calomys species, the maximum percentage of fertilized eggs was obtained after pre-incubation with $10^{7}$ spermatozoa $\mathrm{ml}^{-1}$ and insemination in vitro with $10^{6}$ spermatozoa $\mathrm{ml}^{-1}$. These results confirm that TALP medium and a concentration of $10^{7}$ spermatozoa $\mathrm{ml}^{-1}$ for pre-incubation are appropriate for capacitation leading to fertilization in vitro. Moreover, in both species, optimal percentages for hyperactivation were obtained for this medium at $60 \mathrm{~min}$ of incubation and $10^{7}$ spermatozoa $\mathrm{ml}^{-1}$. Furthermore, these conditions produced only $20-30 \%$ of spontaneously reacted spermatozoa at the time chosen for in vitro insemination; the percentage of acrosome-reacted spermatozoa subsequently increased up to $120 \mathrm{~min}$ of incubation.

In the last two decades the characterization of gametes in small rodents such as the mice, rats and hamsters has advanced considerably. At present, these species are commonly used as models for reproductive studies. However, mammalian fertilization is a complicated process, and understanding of the basis of species-specificity and the molecular mechanisms underlying the whole reproductive process will require evidence from a wider variety of species. It is expected that C. musculinus and C. laucha will be useful laboratory animals from which to gain further understanding of mammalian reproduction.

The authors are grateful to Claudio Barros for providing the opportunity to do the sperm penetration assay in his laboratory. This work was supported by a grant from Fundación Antorchas (Argentina).

\section{References}

Bavister BD (1989) A consistently successful procedure for in vitro fertilization of golden hamster eggs Gamete Research 23 139-158

Bavister BD and Yanagimachi R (1977) The effects of sperm extracts and energy sources on the motility and acrosome reaction of hamster spermatozoa in vitro. Biology of Reproduction 16 228-237

Bavister BD, Rogers BJ and Yanagimachi R (1978) The effect of cauda epididymal plasma on the motility and acrosome reaction of hamster and guinea pig spermatozoa in vitro. Biology of Reproduction 19358-363

Chaudhuri JP and Yanagimachi R (1984) An improved method to visualize human sperm chromosomes using zona-free hamster eggs Gamete Research $10233-239$

Childs JE, Mills JN and Glass GE (1995) Rodent-borne hemorrhagic fever viruses: a risk for mammalogists? Journal of Mammalogy 76 664-680

Fulton BP and Whittingham DG (1978) Activation of mammalian oocytes by intracellular injection of calcium Nature 273 149-151

Hodara VL, Kajon AE, Quintans C, Montoro L and Merani MS (1984) Parámetros métricos y reproductivos de Calomys musculinus (Thomas, 1913) y Calomys callidus Thomas, 1916 (Rodentia, Cricetidae) Revista del Museo Argentino de Ciencias Naturales 13 453-459

Hodara VL, Espinosa MB and Merani MS (1989) Calomys laucha (Rodentia, Cricetidae): growth and breeding in laboratory conditions Laboratory Animals 23 340-344

Lasserre A, Espinosa MB and Vitullo AD (1998) Superovulation in vesper mouse Calomys musculinus (Rodentia-Sigmodontinae) Biocell 22 157-162

Lasserre A, Cebral E and Vitullo AD (1999a) Superovulation in vesper mouse Calomys laucha: a biomedical model for hantavirus and arenavirus Laboratory Animals 33 1-8

Lasserre A, Cebral E and Vitullo AD (1999b) The kinetics of oocyte activation and dynamics of polar body formation in Calomys musculinus and Calomys laucha (Rodentia-Sigmodontinae) Zygote 7 347-356

Meizel S, Lui CW, Working PK and Mrsny RJ (1980) Taurine and hipotaurine: the effect on the motility, capacitation and acrosome reaction of hamster sperm in vitro and their presence in sperm and reproductive tract of several mammals Development Growth and Differentiation 22 483-494

Mills JN, Ellis BA, Childs JE, McKee KT, Maiztegui JI, Peters CJ, Ksiazek TG and Jahrling PB (1994) Prevalence of infection with Junin virus in rodent populations in the epidemic area of Argentine hemorragic fever American Journal of Tropical Medicine and Hygiene 51 554-562

Mrsny RJ, Waxman L and Meizel S (1979) Taurine maintains and stimulates motility of hamster sperm during capacitation in vitro. Journal of Experimental Zoology 210 123-128

Niwa K and Chang MC (1974) Optimal sperm concentration and minimum number of spermatozoa for fertilization in vitro of rat eggs Journal of Reproduction and Fertility 40 471-474

Reig OA (1984) Distibuçao geográfica e história evolutiva dos roedores muroideos Sulamericanos (Cricetidae: Sigmodontinae) Brazilian Journal of Genetics $7333-365$

Suarez SS (1988) Hamster sperm motility transformation during development of hyperactivation in vitro and epididymal maturation Gamete Research 1951-65

Toyoda Y, Yokoyama M and Hoshi T (1971) Studies on the fertilization of mouse eggs in vitro. Effect of in vitro pre-incubation of spermatozoa on time of sperm penetration of mouse eggs in vitro. Japanese Journal of Animal Reproduction 16 152-157

Weissenbacher MC, Laguens RP and Coto C (1987) Argentine hemorragic fever Current Topics in Microbiology and Immunology 134 79-116

Weissenbacher MC, Merani MS, Hodara VL, de Villafañe G, Gajdusek DC, Chu YX and Lee HW (1990) Hantavirus infection in laboratory and wild rodents in Argentina Medicina 50 43-46

Wood M (1987) Chapter 5. In Mammalian Preimplantation Embryos: A Practical Approach pp 81-99 Ed. M Monk. IRL Press, England

Yanagimachi R (1970) In vitro capacitation of golden hamster spermatozoa by homologous and heterologous blood sera Biology of Reproduction 3 147-153

Yanagimachi R (1972) Fertilization of guinea pig eggs in vitro. Anatomical Record 174 9-20

Yanagimachi R (1984) Zona-free hamster eggs: their use in assessing fertilizing capacity and examining chromosomes of human spermatozoa Gamete Research 10 187-232 